\title{
Natural killer cell monitoring in cutaneous melanoma - new dynamic biomarker
}

\author{
GHEORGHIȚA ISVORANU ${ }^{1}$, MIHAELA SURCEL ${ }^{2,3}$, RADU-IONUȚ HUICĂ $\breve{~}^{2,4}$, \\ ADRIANA NARCISA MUNTEANU ${ }^{2,3}$, IOANA RUXANDRA PIRVU ${ }^{2}$, DAN CIOTARU $^{2}$, \\ CAROLINA CONSTANTIN ${ }^{2,5}$, OVIDIU BRATU ${ }^{6,7}$, MONICA NEAGU $^{2,3,5}$ and CORNEL URSACIUC ${ }^{2}$
}

\author{
${ }^{1}$ Animal Husbandry and ${ }^{2}$ Immunobiology Laboratory, 'Victor Babeș’ National Institute of Pathology, 050096 Bucharest; \\ ${ }^{3}$ Doctoral School of Biology, Faculty of Biology, University of Bucharest, 050095 Bucharest; ${ }^{4}$ Division of Cellular and \\ Molecular Biology and Histology, 'Carol Davila' University of Medicine and Pharmacy, 050474 Bucharest; ${ }^{5}$ Department of \\ Pathology, Colentina University Hospital, 020125 Bucharest; ${ }^{6}$ Clinical Department 3, Central Military Hospital, \\ 010825 Bucharest; ${ }^{7}$ Academy of Romanian Scientists, 050085 Bucharest, Romania
}

Received September 21, 2018; Accepted December 20, 2018

DOI: $10.3892 / 01.2019 .10069$

\begin{abstract}
Melanoma is responsible for most skin cancer deaths in humans. The immune system plays a major role in regulating tumor cell proliferation by initiating defence responses against tumor aggression. Research on murine cancer models allow for a better understanding of immune response in malignancies, revealing specific changes of the immune status in the presence of tumors. Melanoma resistance to conventional therapies and its high immunogenicity justify the development of new therapies. These features reinforce melanoma as a suitable model for studying antitumor immunity. Recent findings on NK cell activation in cancer patients indicate that several important parameters,
\end{abstract}

Correspondence to: Dr Monica Neagu, Immunobiology Laboratory, 'Victor Babes' National Institute of Pathology, 99-101 Splaiul Independentei, 050096 Bucharest, Romania

E-mail: neagu.monica@gmail.com

Abbreviations: APC, allophycocyanin; BD, Becton-Dickinson; $\mathrm{CD}$, cluster of differentiation; E:T, effector:target; FACS, fluorescence-activated cell sorting; FBS, fetal bovine serum; FITC, fluorescein isothiocyanate; IFN, interferon; Ig, immunoglobulin; IL, interleukin; K2-EDTA, Kalium 2 ethylenediaminetetraacetate; KLRG1, killer cell lectin-like receptor G1; LDH, lactate dehydrogenase; LAMP-1, lysosome-associated membrane protein-1; MbM, melanoma-bearing mice; MHC, major histocompatibility complex; NK, natural killer; $\mathrm{PB}$, peripheral blood; PBMCs, peripheral blood mononuclear cells; PE, phycoerythrin; PE/Cy, phycoerythrin complex with cyanine; $\mathrm{PerCP} / \mathrm{Cy}$, peridinin chlorophyll protein complex with cyanine; R, receptor; RPMI, Roswell Park Memorial Institute; SD, standard deviation; TNFR, tumor necrosis factor receptor

Key words: T-lymphocytes, melanoma, tumor-bearing mice, NK cells, B-lymphocytes such as tumor capacity to modulate the function and phenotype of NK cells, require consideration for the choice of an NK-based therapy. In this study, we investigated T-CD4 ${ }^{+}$ and $\mathrm{T}-\mathrm{CD}^{+}$lymphocytes, B lymphocytes and NK cells in peripheral blood and spleen cells suspension from melanomabearing mice compared to healthy controls in order to assess the potential for tumor growth-promoting immunosuppression. Our results indicate that in a melanoma-bearing mouse model the percentage of NK cells in spleen is reduced and that their phenotype is different compared to control mouse NK cells.

\section{Introduction}

Cutaneous melanoma has a high incidence and it is responsible for most skin cancer deaths in humans, the main risk factor being exposure to ultraviolet radiation. According to World Health Organization, 132,000 melanoma skin cancers occur globally each year. Cutaneous melanoma is the most aggressive type of skin cancer, with a high resistance to classical therapies as chemotherapy and radiotherapy (1). Melanoma is usually highly immunogenic and spontaneous remissions have been observed $(2,3)$.

The immune system plays a major role in regulating tumor cell proliferation by initiating defence responses against tumor aggression. In recent years, there has been increasing interest in understanding the role of the immune system in tumor development and progression (4-6). In melanoma, skin's immune system and tumor cells are interconnected from the very beginning of the tumorigenesis process, including initiation, progression, tumor invasion and metastasis. The cellular components of the skin immune system, in particular regulatory $\mathrm{T}$ cells, $\mathrm{NK}$ and dendritic cells, are the main components of the immunosuppressive network. The failure of antitumor immune response stems from alterations of local immune suppressor cells and factors. In this complex microenvironment, interactions of melanocytes with these factors can lead to malignant transformation (7). 
Recent studies reflect the concern to identify immune markers by minimally invasive methods to monitor and guide the treatment in skin melanoma. NK and dendritic cells, important components of innate immune surveillance, have not been extensively studied in peripheral blood (PB) in cutaneous melanoma; however, recent data indicate a significant alteration of NK cells: A decrease in their activity, a reduction in the percentage of IFN- $\gamma$ secreting NK cells and a predominance of the CD16 ${ }^{\mathrm{dim} / \mathrm{neg}^{-}}$subpopulation (8).

There is strong evidence that an effective innate immune response plays an important role in tumor growth and progression. NK cells are innate effector cells that substantially contribute to antitumor immune responses, low activity of PB NK cells is associated with an increased risk of cancer (9). Monitoring NK cell functions is important in diagnosis, prognosis, or follow-up during therapy in many diseases, including cancer (10). NK cells have the ability to induce direct cytotoxicity of target cells, without prior sensitization. Target recognition and effector function by NK cells are controlled by both activating and inhibitory receptors signals.

NK cells are a heterogeneous population divided into different subsets that can be defined both functionally and by a combination of surface markers (11-13). Based on the CD56 expression, two human NK subsets have been identified, $\mathrm{CD}^{\mathrm{dim}}$ and CD56 ${ }^{\text {bright }}$. CD56 ${ }^{\mathrm{dim}}$ cellular subset has cytotoxic function and is found mostly in PB, while CD56 $6^{\text {bright }}$ subset has a lower cytolytic activity and is found mainly in lymphoid organs. Mouse NK cells can be subdivided into 4 differentiation stages based on surface density expression of CD27 and CD11b (14). The maturation of NK cells appears to be a continuous process that starts with a double negative stage, CD27-CD11b cells (the most immature stage) and ends with $\mathrm{CD} 27^{-} \mathrm{CD} 11 \mathrm{~b}^{+}$phenotype, most mature cells $(15,16)$. In healthy mice the majority of $\mathrm{CD} 11 \mathrm{~b}^{+} \mathrm{NK}$ cells are found in peripheral organs such as the spleen, blood, liver and lung (17).

The purpose of this study, was to characterize T-CD4 ${ }^{+}$and T-CD8 ${ }^{+}$lymphocytes, B lymphocytes and NK cells in both PB and secondary lymphoid organ like the spleen from melanoma-bearing mice (MbM). The investigation aimed through these cellular populations to assess the immunosuppression potential of the tumor in order to find the best peripheral immune cell population that can be further developed as an indicator of tumor evolution.

\section{Materials and methods}

Animal strain. C57BL/6 mice (males and females), 8-10 weeks old, purchased from Jackson Laboratory (Bar Harbor, ME, USA), were provided by the Animal Husbandry of Victor Babes National Institute of Pathology. The animals were maintained in optimal conditions: temperature $22 \pm 2^{\circ} \mathrm{C}$, humidity $55 \pm 10 \%$, artificial ventilation, lighting $12 / 12$, light/dark cycle. The mice received food (special granulated fodder for mice) and water (filtered and sterilized) ad libitum. They were accommodated in different special cages with bedding according to sex, with an optimal density of individuals per cage. All mice were kept under a rigorous cleaning and hygiene program and were monitored daily. The experiments were done in accordance with recognized principles of Laboratory Animal Care in the framework of EU Directive 2010/63/EU for animal experiments (18). The study was approved by the Ethics Committee from 'Victor Babeș' Institute and by the National Sanitary Veterinary and Food Safety Authority through project authorization, no. 388/22.03.2018 (Bucharest, Romania).

Murine experimental model of melanoma. We developed the standard animal model for cutaneous melanoma using C57BL/6 mice by inoculating subcutaneously in the right flank (day 1) $0.5 \times 10^{6}$ B16-F10 (ATCC ${ }^{\circledR}$ CRL-6475 ${ }^{\mathrm{TM}}$; ATCC, Manassas, VA, USA) melanoma cells line/mouse. Tumorbearing mice were housed in separate boxes from healthy animals, under the same feeding and microclimate conditions.

Two groups of C57BL/6 mice were considered (8-10 weeks old, 1:1 sex ratio): i) the control group (20 mice) - healthy mice; ii) the melanoma group (15 mice) - inoculated with B16-F10 cells on day 1 and sacrificed on day 21 of the experiment.

Tumor growth monitoring. Two perpendicular diameters of the developed tumors were measured weekly using a calliper. The tumor volume was calculated by the following formula: Tumor volume $=4 \pi r 3 / 3$, where $r$ is the mean of the two perpendicular diameters (19).

Blood and tissues sampling. On day 21 of the experiment all animals were anesthetized with ketamine/acepromazine cocktail (ketamine $100 \mathrm{mg} / \mathrm{kg}$, ketamin 10\%, Medistar Arzneimittelvertrieb Gmbh, Ascheberg, Germany; acepromazine $5 \mathrm{mg} / \mathrm{kg}$, Calmivet Solution Injectable Acepromazine $5 \mathrm{mg}$, Vétoquinol SA, Lure, France) prior to blood collection and spleen sampling, then sacrificed. Blood was collected by retro-orbital veni-puncture in K2-EDTA coated tubes (Microvette, Sarstedt AG \& Co., Numbrecht, Germany).

Isolation of spleen cells. Spleens were harvested in RPMI-1640 media supplemented with $5 \%$ fetal bovine serum (FBS) (Biochrom GmbH, Berlin, Germany); spleen cell suspensions were prepared by mechanical disruption and passed through a $70 \mu \mathrm{m}$ cell strainer (BD Falcon; BD Biosciences, San Jose, CA, USA). The cell suspensions were centrifuged at $350 \mathrm{xg}$ for $5 \mathrm{~min}\left(20^{\circ} \mathrm{C}\right)$ and resuspended in RBC Lysis Buffer (BioLegend, San Diego, CA, USA). After 5-min incubation on ice, the cell lysis was stopped by adding $10 \mathrm{ml}$ Cell Staining Buffer (BioLegend). Cell suspensions were centrifuged at $350 \mathrm{x} \mathrm{g}$ for $5 \mathrm{~min}\left(20^{\circ} \mathrm{C}\right)$ and the cell pellet was resuspended twice in Cell Staining Buffer. Viable cells were counted and resuspended in Cell Staining Buffer at $1 \times 10^{6}$ cells $/ \mathrm{ml}$.

Flow cytometry analysis. Lymphocyte immunophenotyping and NK degranulation assays were performed by flow cytometry, based on the expression of surface or intracellular markers. Unlabeled cells were used as controls; nonspecific fluorescence signals due to spectral overlap were automatically compensated (UltraComp eBeads; Thermo Fischer Scientific, Inc., San Diego, CA, USA). Data acquisition and analysis were performed on a BD FACSCanto II cytometer with BD FACSDiva v.6.1 software (BD Biosciences).

Immunophenotyping of lymphocytes. Blood samples and spleen cell suspensions were incubated with TruStain fcX (anti-mouse CD16/32) antibody (clone 93; isotype Rat IgG2a, $\lambda$; diluted 2/100, cat. no. 101319; BioLegend, 
San Diego, CA, USA) in order to block non-specific antibody binding, then stained for $20 \mathrm{~min}$ at room temperature with the following antibodies: Alexa Fluor 647 anti-mouse CD3e (clone 145-2C11, isotype Armenian Hamster IgG, diluted 0.5/100, cat. no. 100322), PE/Cy7 anti-mouse CD4 (clone GK1.5, isotype Rat IgG2b, $\kappa$, diluted 1.25/100, cat. no. 100422), Alexa Fluor 488 anti-mouse CD8a (clone 53-6.7, isotype Rat IgG2a, $\kappa$, diluted 0.5/100, cat. no. 100723), PerCP/Cy5.5 anti-mouse CD19 (clone 6D5, isotype Rat IgG2a, $\kappa$, diluted 1.25/100, cat. no. 115534) and PE anti-mouse NK1.1 (clone PK136, isotype mouse IgG2a, $\kappa$, diluted 1.25/100, cat. no. 108708) (all from BioLegend). Surface staining for blood samples was followed by red blood cell lysis with RBC Lysis Buffer (BioLegend) for $10 \mathrm{~min}$ at room temperature in the dark and centrifugation at $350 \mathrm{x} \mathrm{g}$ for $5 \mathrm{~min}, 20^{\circ} \mathrm{C}$. Cells were washed twice with Cell Staining Buffer (BioLegend) and analysed by flow cytometry.

NK cells phenotype. Blood samples and spleen cell suspensions were labelled according to the above described protocol, with the following monoclonal antibodies: BV 510 anti-mouse NK1.1 (clone PK136, isotype mouse IgG2a, $\kappa$, diluted 5/100, cat. no. 108738), FITC anti-mouse CD3e (clone 145-2C11, isotype Armenian Hamster IgG, diluted 1/100, cat. no. 152304), $\mathrm{PE} / \mathrm{Cy} 7$ anti-mouse CD335 (NKp46) (clone 29A1.4, isotype rat IgG2a, $\kappa$, diluted 5/100, cat. no. 137618), PE/Cy7 anti-mouse CD69 (clone H1.2F3, isotype Armenian Hamster IgG, diluted 5/100, cat. no. 104511), APC/Cy7 anti-mouse CD45R (B220) (clone RA3-6B2, isotype Rat IgG2a, $\kappa$, diluted 1.25/100, cat. no. 103223), PerCP/Cy5.5 anti-mouse CD11c (clone N418, isotype Armenian Hamster IgG, diluted 5/100, cat. no. 117328), APC/Cy7 anti-mouse CD43 (clone 1B11, isotype Rat IgG2a, $\kappa$, diluted 1.25/100, cat. no. 121219), PerCP/Cy5.5 anti-mouse/ rat/human CD27 (clone LG.3A10, isotype Armenian Hamster IgG, diluted 1.25/100, cat. no. 124213), APC/Cy7 anti-mouse CD25 (IL-2R $\alpha$ ) (clone PC61, isotype Rat IgG1, $\lambda$, diluted 5/100, cat. no. 102025), PerCP/Cy5.5 anti-mouse CD122 (IL-2R/ IL-15R $\beta$ ) (clone TM- $\beta 1$, isotype Rat IgG2b, $\kappa$, diluted 2.5/100, cat. no. 123211), PE anti-mouse CD132 (common $\gamma$ chain) (clone TUGm2, isotype Rat IgG2b, $\kappa$, diluted 5/100, cat. no. 132305) (all from BioLegend), eFluor 450 anti-mouse CD49b (DX5) (clone DX5, isotype Rat IgM, $\kappa$, diluted 5/100, cat. no. 48-5971-82), APC anti-mouse CD11b (clone M1/70, isotype Rat IgG2b, $\kappa$, diluted 2.5/100, cat. no. 50-0112-80), PE anti-mouse KLRG1 (clone 2F1, isotype Syrian Hamster IgG, diluted 1.25/100, cat. no. 12-5893-80) (all from eBioscience Inc., San Diego, CA, USA).

NK antitumoral activity measured as degranulation capacity. CD107a (LAMP-1) conjugated with APC/Cy7 was used to measure NK cell degranulation after exposure to YAC-1 tumour target cells. The cell suspension obtained from splenocytes was incubated with or without target cells at an E:T ratio $=2 / 1$ for $1 \mathrm{~h}$. The APC/Cy7 anti-mouse CD107a (clone 1D4B, isotype Rat IgG2a, $\kappa$, diluted 5/100, cat. no. 121616; BioLegend) antibody and GolgiStop (BD GolgiStop; BD Biosciences) reagent (diluted 1/151) were then added and cell were incubated for $3 \mathrm{~h}$. Next, cells were labelled with anti-CD3 (FITC anti-mouse CD3e, clone 145-2C11, isotype Armenian Hamster IgG; BioLegend) and NK1.1 (BV 510 anti-mouse NK1.1, clone PK136, isotype Mouse IgG2a, $\kappa)$ (BioLegend) according to the protocol described before, and analyzed by flow cytometry.

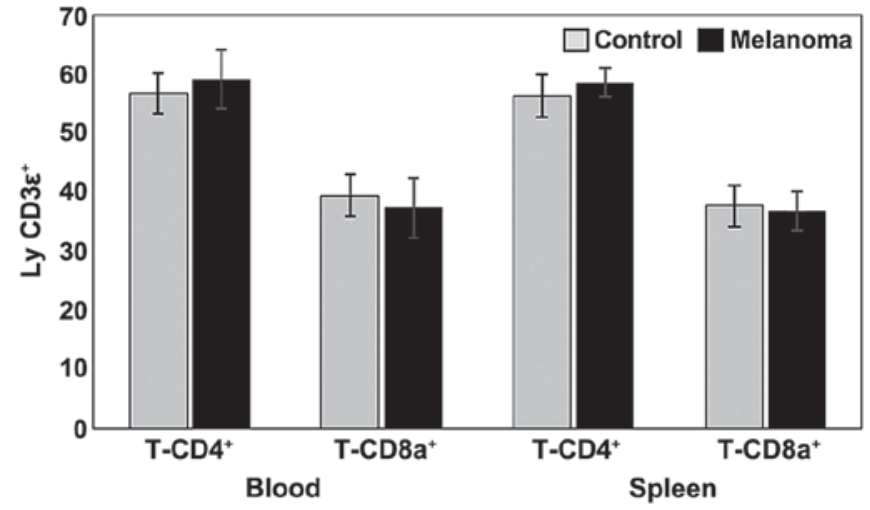

Figure 1. Distribution of T-lymphocyte subpopulations in PB and spleen cell suspension. Percentage distribution of T-CD4 ${ }^{+}$and T-CD8 $\mathrm{a}^{+}$lymphocytes in $\operatorname{MbM}(\mathrm{n}=10)(59 \pm 5$ and $37 \pm 5$ in $\mathrm{PB} ; 59 \pm 2$ and $37 \pm 3$ in spleen suspensions), and the control group $(n=10)(57 \pm 3$ and $40 \pm 4$ in $P B ; 57 \pm 4$ and $38 \pm 4$ in spleen cells suspension). The results are presented as percentage of $\mathrm{CD} 3 \varepsilon^{+}$lymphocytes $($ mean $\pm \mathrm{SD})$.

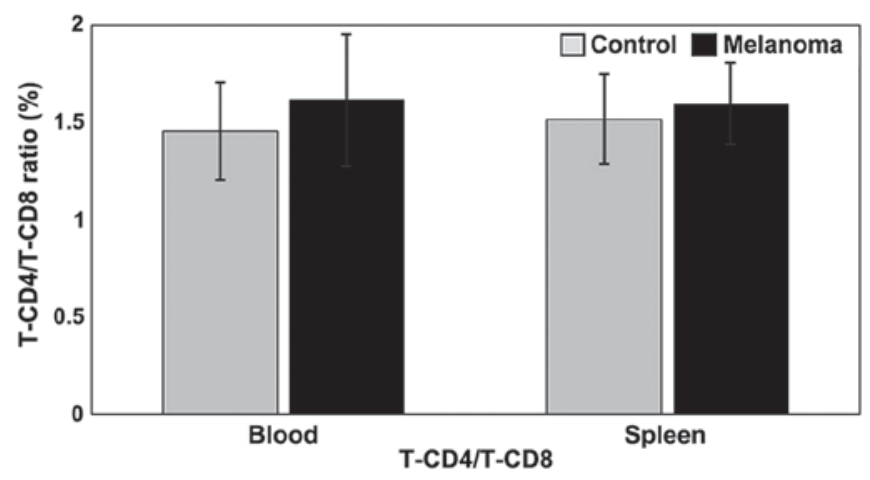

Figure 2. Distribution of T-CD4/T-CD8 ratio in PB and spleen cell suspension. Distribution of T-CD4/T-CD8 ratio in MbM $(n=10)(1.62 \pm 0.3$ in PB and $1.60 \pm 0.2$ in spleen cells suspension) and the control group $(n=10)(1.46 \pm 0.3$ in PB and $1.52 \pm 0.2$ in spleen cells suspension). The results are presented as mean values $\pm \mathrm{SD}$.

Lactate dehydrogenase ( $\mathrm{LDH}$ ) release assay. NK cell cytotoxicity was determined with CytoTox 96 Non-Radioactive Cytotoxicity assay (Promega Co., Madison, WI, USA) using YAC-1 cells as target cell line (ATCC ${ }^{\circledR}$ TIB-160). This colorimetric assay quantitatively measures $\mathrm{LDH}$, a stable cytosolic enzyme that is released upon cell lysis, in much the same way that ${ }^{51} \mathrm{Cr}$ is released in a radioactive assay. Briefly, spleen cells (effector cell, E) and YAC-1 cells $\left(2 \times 10^{4}\right.$ cells/well; targeted cell, T) were mixed in different E:T ratios (20:1 and 10:1) in a 96-well and incubated at $37^{\circ} \mathrm{C}$ with $5 \% \mathrm{CO}_{2}$ overnight according to the manufacturer's instructions. The effector:target cellular ratio and incubation time were prior tested to optimize the experimental conditions. The NK cell cytotoxicity of effector cells was measured at $490 \mathrm{~nm}$ (Absorbance Microplate Reader Sunrise; Tecan, Grödig, Austria) and was calculated using the following equation: (Experimental - Effector Spontaneous - Target Spontaneous)/(Target Maximum - Target Spontaneous) x 100, where 'Experimental' is the experimental LDH release of co-cultured effector and target cells, 'Effector Spontaneous' and 'Target Spontaneous' express the spontaneous released LDH of the effector and target cells alone, 
respectively, and 'Target Maximum' is the maximum LDH release of target cells.

Statistical analysis. Data analysis was performed using BD FACSDiva (v.6.1 software; BD Biosciences), with $\mathrm{CD} 3 \varepsilon^{+}$lymphocytes gated as $\mathrm{CD} 4{ }^{+} \mathrm{CD} 8 \mathrm{a}^{-}$and $\mathrm{CD} 4{ }^{-} \mathrm{CD} 8 \mathrm{a}^{+}$ populations, and $\mathrm{CD} 3 \varepsilon^{-}$lymphocytes as $\mathrm{CD} 19^{+} \mathrm{NK} 1.1^{-}$and CD19-NK1.1 $1^{+}$populations. Unlabeled cells were used as controls; nonspecific fluorescence signals due to spectral overlap were automatically compensated. Data was analysed using Microsoft Excel (Microsoft, Redmond, CA, USA). Results are presented as mean \pm SD of cells percentage. For statistical analysis, the Student's t-test (two-tailed, assuming equal variance) was used for statistical evaluation of the differences between the experimental groups. P-value $<0.05$ was considered to indicate a statistically significant difference.

\section{Results}

Immunophenotyping of lymphocytes. In order to assess the immune cell status of MbM, T, B and NK cell populations were analysed by flow cytometry. The results were expressed as a percentage from the $\mathrm{CD}^{+}$lymphocytes, respectively $\mathrm{CD}^{-}$lymphocytes (mean $\pm \mathrm{SD}$ ) (Figs. 1 and 3).

Analysis of $\mathrm{T}$ cell subpopulations in melanoma mice showed a slight increase in the percentage of T-CD4+ lymphocytes in both PB and spleen cell suspension. The percentages of $\mathrm{T}-\mathrm{CD} 8^{+}$lymphocytes were lower in $\mathrm{MbM}$ compared to the control group (in both PB and spleen cell suspension) but with no statistical significance (Fig. 1). T-CD4/T-CD8 ratio is higher in MbM compared to control group, but the differences between experimental groups are not statistically significant (Fig. 2).

Analysis of B lymphocytes and NK cells revealed statistically significant differences between the two experimental groups in both $\mathrm{PB}$ and spleen cell suspension. B-CD19 ${ }^{+}$lymphocytes were significantly decreased in $\mathrm{MbM}\left(68 \pm 9, \mathrm{p}=2 \times 10^{-7}\right.$ in $\mathrm{PB} ; 29 \pm 18, \mathrm{p}=2 \times 10^{-9}$ in spleen cell suspension) compared to the control group $(85 \pm 2$ in $\mathrm{PB} ; 81 \pm 5$ in spleen cell suspension). Percentages of NK1.1 ${ }^{+}$cells increased significantly in melanoma-bearing mice in the PB $(9 \pm 5, \mathrm{p}=0.001)$ and decreased in spleen cells suspension $\left(2 \pm 1, \mathrm{p}=7 \times 10^{-6}\right)$ compared to the control group $(4 \pm 1$ in $\mathrm{PB}$, respectively $6 \pm 2$ in spleen cell suspension) (Fig. 3).

NK cells phenotype. A large panel of surface markers was investigated in PB and spleen cell suspension to assess NK cells phenotype, thus lineage markers: CD161 (NK1.1), CD3e; activation and maturation markers: CD335 (NKp46), CD69, CD45R (B220), CD11c, CD49b (DX5), CD11b, CD43, CD27, KLRG1; markers for cytokine receptors: CD25 (IL-2R $\alpha$ ), CD122 (IL-2R/IL-15R $\beta$ ), CD132 (common $\gamma$ chain).

Our experimental data suggested a decrease in NKp46 (activating receptor) expression in both $\mathrm{PB}$ and spleen cell suspension for $\mathrm{MbM}$ compared to the control group. Significant differences between the two experimental groups were observed in PB (p<0.05) (Fig. 4).

For activation and maturation markers of $\mathrm{NK}$ cells (CD69, B220, CD11c), the main change observed in PB is

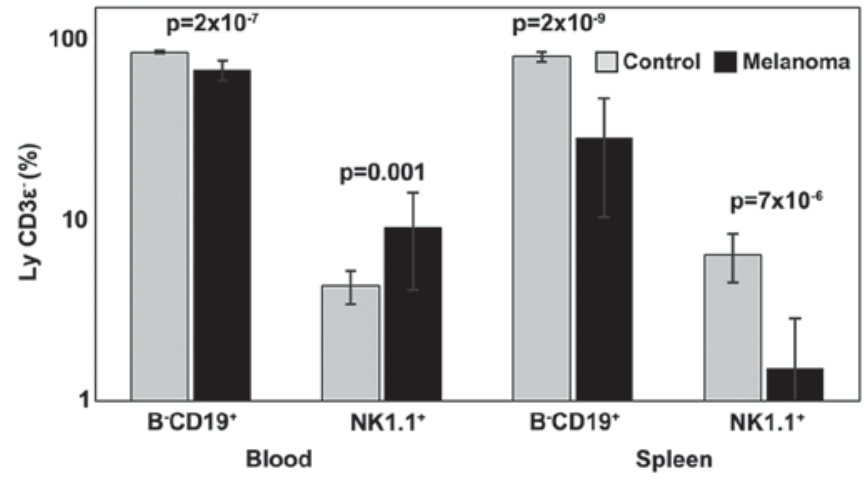

Figure 3. Distribution of B-lymphocytes and NK cells in PB and spleen cell suspension. B-CD19+ lymphocytes and NK1.1 cells in MbM $(n=10)(68 \pm 9$, $\mathrm{p}=2 \times 10^{-7}$, and $9 \pm 5, \mathrm{p}=0.001$ in $\mathrm{PB} ; 29 \pm 18, \mathrm{p}=2 \times 10^{-9}$, and $2 \pm 1, \mathrm{p}=7 \times 10^{-6}$ in spleen cell suspension) and the control group $(n=10)(85 \pm 2$ and $4 \pm 1$ in $P B$; $81 \pm 5$ and $6 \pm 2$ in spleen cell suspension). The results are presented as percentage from $\mathrm{CD} 3 \varepsilon^{-}$lymphocytes (mean $\pm \mathrm{SD}$ ).

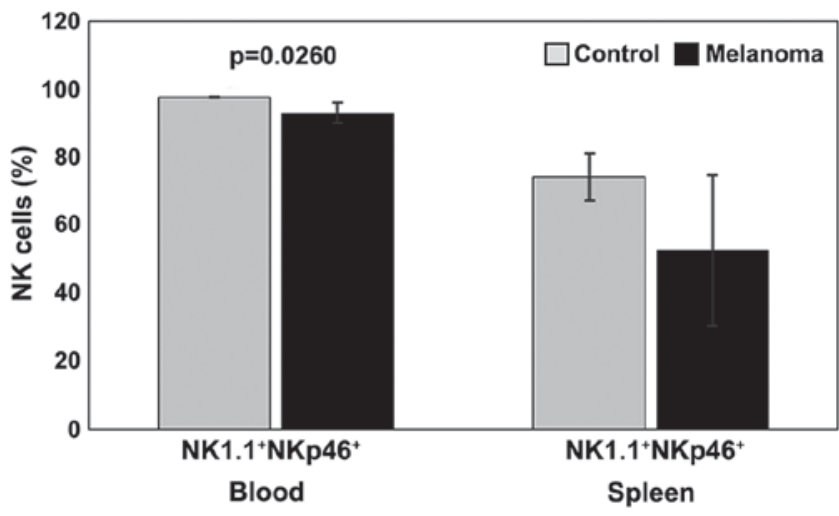

Figure 4. Distribution of NK1.1 $1^{+} \mathrm{NK} 46^{+}$population in $\mathrm{PB}$ and spleen cell suspension. $\mathrm{NK} 1.1^{+} \mathrm{NKp} 46^{+}$cells in $\mathrm{MbM}(\mathrm{n}=5)$ in $\mathrm{PB}(93 \pm 3.1, \mathrm{p}=0.026)$ and spleen cell suspension $(53 \pm 22.2)$ as compared to control group $(n=5)(98 \pm 0.2$ in $\mathrm{PB} ; 74 \pm 6.9$ in spleen cell suspensions). The results are presented as percentage from $\mathrm{NK} 1.1^{+}$cells (mean $\pm \mathrm{SD}$ ).

the significant decrease of CD11c in melanoma ( $<<0.05)$; the levels of expression for CD69 and B220 are similar for the two experimental groups (Fig. 5A). An increased expression of these activation markers was observed, on the other hand, in the spleen cell suspension. Significant differences $(\mathrm{p}<0.05)$ were obtained between the experimental groups for all three activation/maturation markers analyzed (Fig. 5B).

Analysis of $\mathrm{B} 220$ and $\mathrm{CD} 11 \mathrm{c}$ on $\mathrm{NK} 1.1^{+}$cells revealed that in control tumor-free mice, the $\mathrm{B} 220^{+} \mathrm{CD} 11 \mathrm{c}^{+} \mathrm{NK} 1.1^{+}$subset in both PB and spleen cell suspension was at $\sim 3 \%$ of NK1.1 $1^{+}$cells. In tumor-bearing mice, a decrease in the percentage of $\mathrm{B} 220^{+} \mathrm{CD} 11 \mathrm{c}^{+} \mathrm{NK} 1.1^{+}$cells in the $\mathrm{PB}$ was observed, as well as a significant increase in the spleen $(\mathrm{p}<0.01)$ (Fig. 6).

In PB, analysis of CD49b, CD11b, CD43 and KLRG1 expression revealed similar levels for the two experimental groups. The expression of CD27 is downregulated- in MbM, and the differences between the experimental groups are significant ( $\mathrm{p}=0.001)$ (Fig. 7A). Significantly lower levels of NK cells expressing CD49b, CD11b, CD43 and KLRG1 were observed in spleen cell suspension in MbM compared to the control group $(\mathrm{p}<0.05)$. NK cells expressing CD27 are slightly 
A

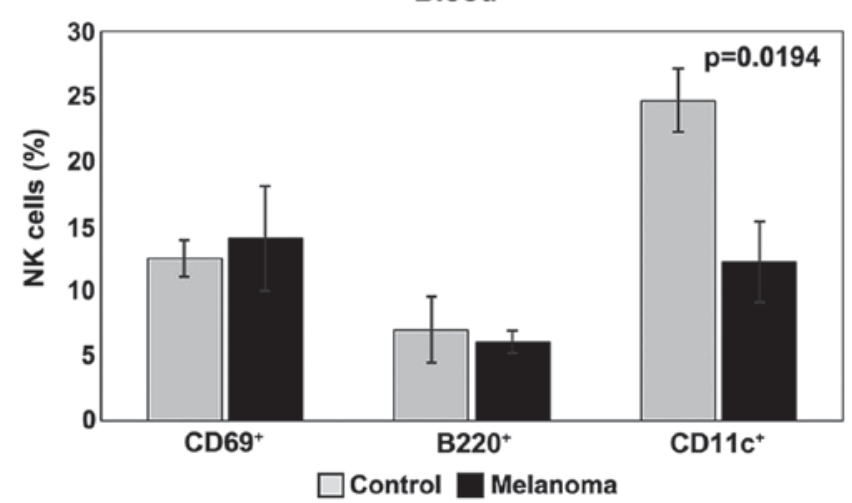

B

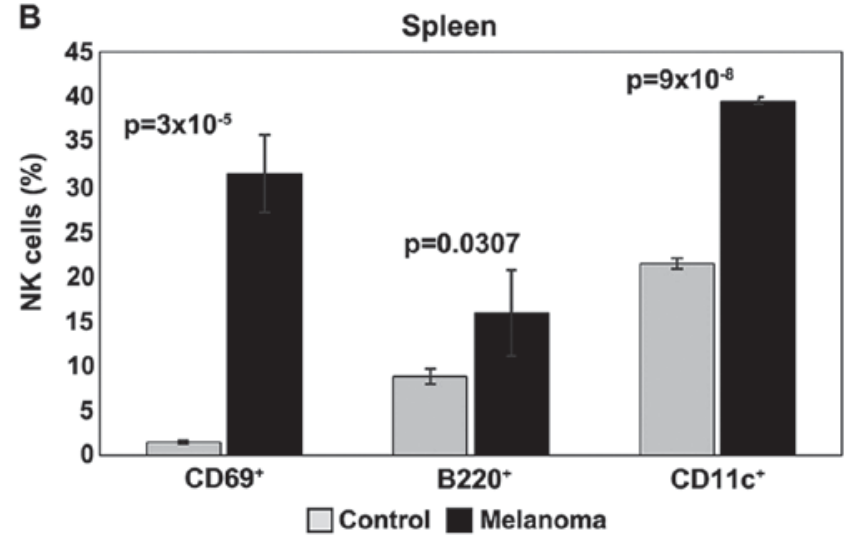

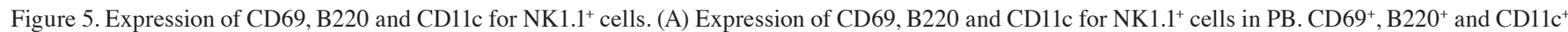
cells in MbM (n=5) $(14 \pm 4,6 \pm 0.9$ and 12 $\pm 3.1, \mathrm{p}=0.0194)$ as compared to control group ( $\mathrm{n}=5)(12 \pm 1.4,7 \pm 2.6$ and $25 \pm 2.4)$ in PB. (B) Expression of CD69, B220 and CD11c for NK1. $1^{+}$cells in spleen cell suspension. $\mathrm{CD} 69^{+}, \mathrm{B} 220^{+}$and $\mathrm{CD} 11 \mathrm{c}^{+}$cells in $\mathrm{MbM}(\mathrm{n}=5)\left(31 \pm 4.4, \mathrm{p}=3 \times 10^{-5} ; 16 \pm 4.8, \mathrm{p}=0.0307 ; 40 \pm 0.4, \mathrm{p}=9 \mathrm{x} 10^{-8}\right)$ as compared to control group $(n=5)(2 \pm 0.2,9 \pm 0.8$ and $21 \pm 0.6)$ in spleen cell suspension. The results are presented as a percentage from $\mathrm{NK} 1.1^{+}$cells $(\mathrm{mean} \pm \mathrm{SD})$.

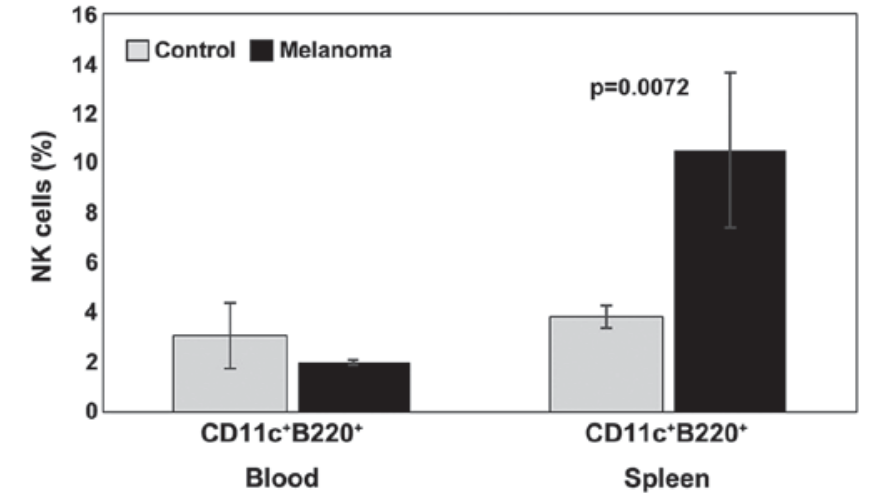

Figure 6. Distribution of $\mathrm{NK} 1.1^{+} \mathrm{CD} 11 \mathrm{c}^{+} \mathrm{B} 220^{+}$cells in $\mathrm{PB}$ and spleen cell suspension. $\mathrm{CD} 11 \mathrm{c}^{+} \mathrm{B} 220^{+}$cells in $\mathrm{MbM}(\mathrm{n}=5)$ in $\mathrm{PB}(2 \pm 0.1)$ and spleen cell suspension $(11 \pm 3.1, \mathrm{p}=0.0072)$ and the control group $(n=5)(3 \pm 1.3$ in $\mathrm{PB}$; $4 \pm 0.55$ in spleen cell suspensions). The results are presented as percentage from NK1.1 $1^{+}$cells (mean $\left.\pm \mathrm{SD}\right)$.

increased in percentage in MbM, with no statistical significance (Fig. 7B).

The distribution of CD27 and CD11b markers can be used to divide murine NK cells into four subsets defining different maturation stages. The $\mathrm{CD} 27^{-} \mathrm{CD} 11 \mathrm{~b}^{-}$phenotype defines immature $\mathrm{NK}$ cells, $\mathrm{CD} 27^{+} \mathrm{CD} 11 \mathrm{~b}^{-}$suggest an early maturation stage, while $\mathrm{CD} 27^{+} \mathrm{CD} 11 \mathrm{~b}^{+}$and $\mathrm{CD} 27^{-} \mathrm{CD} 11 \mathrm{~b}^{+}$ are specific to mature NK cells. In our experimental data, the distribution of mature NK cell subsets in tumor-bearing mice was different from that of healthy mice (Figs. 8 and 9). The analysis of PB NK cells revealed significant differences between MbM and the control mice for immature CD27-CD11b- NK cells ( $\mathrm{p}<0.05$ ), early mature CD27+CD11b $(\mathrm{p}<0.01)$ and mature $\mathrm{CD} 27^{+} \mathrm{CD} 11 \mathrm{~b}^{+}(\mathrm{p}<0.01) \mathrm{NK}$ cells. The $\mathrm{CD} 27^{-} \mathrm{CD}^{-11 b^{+}} \mathrm{NK}$ subset was increased in MbM but without statistical significance (Fig. 9A). CD27-CD11b ${ }^{-}$CD27 ${ }^{+} \mathrm{CD} 11 \mathrm{~b}$ and $\mathrm{CD} 27^{+} \mathrm{CD} 11 \mathrm{~b}^{+} \mathrm{NK}$ subsets in spleen cell suspension revealed increased values for immature $(\mathrm{p}<0.05)$ and early mature $(\mathrm{p}<0.01)$ NK cells, while the percentage of mature $\mathrm{NK}$ cells is lower in MbM than in the control group $(\mathrm{p}<0.01)$. $\mathrm{CD} 27^{-} \mathrm{CD}_{11 b^{+}} \mathrm{NK}$ subset was decreased in MbM, but without statistical significance (Fig. 9B).
Data obtained for the levels of markers for cytokine receptors showed a decreased expression in the common $\gamma$ receptor subunit, both in blood and spleen cell suspension $(\mathrm{p}<0.001)$ in $\mathrm{MbM}$, and a decrease in receptor subunit $\beta$ in spleen $(\mathrm{p}<0.01)$ (Fig. 10A and B). Also, we noted a decrease in IL-2 $\alpha$ receptor subunit $(\mathrm{CD} 25)$ expression in $\mathrm{PB}(\mathrm{p}<0.05)$ in $\mathrm{MbM}$, and an increase in spleen cell suspension $(\mathrm{p}<0.001)$.

Functional evaluation of NK cells. Functional characterization of NK cells from cell suspensions was performed by evaluating the degranulation of NK cells (effector cells) after exposure to target tumor cells (YAC-1 cells) and the release of LDH to evaluate the cytotoxic effect that NK cells exhibit on tumor cells. CD107a expression change is reflecting NK cell degranulation and it was measured by flow cytometry, assessing thus NK cytotoxicity.

In this study a significant decrease in NK cells degranulation capacity (the effector function) was detected in MbM (Fig. 11). The differences between the experimental groups were statistically significant $(\mathrm{p}<0.001)$. Regarding cytotoxicity inflicted upon YAC-1 cells (Fig. 12) the actual differences between studied groups can be seen only in the 10:1 (effector cell:target cell) ratio, with a decrease in melanoma-bearing mice compared to controls.

NK cytotoxicity to tumor target cells was assessed by measuring the release of LDH from dead cells in a culture medium. MbM NK cells showed a lower cytotoxicity against target cells (YAC-1) compared to the control group (Fig. 12). Even though the decrease in cytotoxicity is not statistically significant, the data suggest a decrease of the tumoricidal efficiency of NK cells.

\section{Discussion}

We investigated T-CD4 ${ }^{+}$and T-CD8 ${ }^{+}$lymphocytes, B lymphocytes and NK cells in PB and spleen cell suspension from MbM compared to healthy controls in order to assess the potential for tumor growth-promoting immunosuppression.

Analysis of T cell subpopulations in melanoma mice showed a slight increase in the percentage of $\mathrm{T}-\mathrm{CD} 4^{+}$lymphocytes 

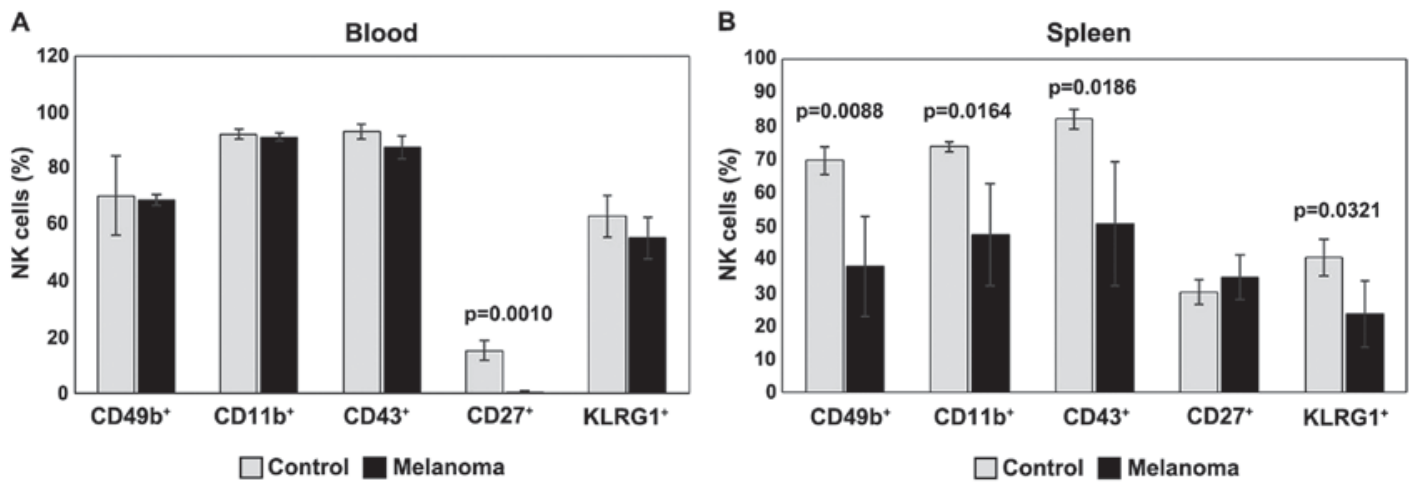

Figure 7. Expression of CD49b, CD11b, CD43, CD27 and KLRG1 for NK1.1 $1^{+}$cells. (A) Expression of CD49b, CD11b, CD43, CD27 and KLRG1 for NK1.1 $1^{+}$cells in PB. CD49b $\mathrm{b}^{+}, \mathrm{CD}_{11} \mathrm{~b}^{+}, \mathrm{CD}_{4} 3^{+}, \mathrm{CD} 27^{+}$and $\mathrm{KLRG1}^{+}$cells in MbM (n=5) $(69 \pm 2 ; 91 \pm 1.4 ; 88 \pm 4 ; 0.4 \pm 0.3, \mathrm{p}=0.001$ and 55 \pm 7.5$)$ as compared to control group ( $\left.\mathrm{n}=5\right)$ (70 $\pm 14.1,92 \pm 1.8,93 \pm 2.6,15 \pm 3.7$ and 63 \pm 7.5$)$ in PB. (B) Expression of CD49b, CD11b, CD43, CD27 and KLRG1 for NK1.1 $1^{+}$cells in spleen cell suspension. CD49b ${ }^{+}$, $\mathrm{CD}_{11} \mathrm{~b}^{+}, \mathrm{CD} 43^{+}, \mathrm{CD} 27^{+}$and $\mathrm{KLRG}^{+}$cells in $\mathrm{MbM}(\mathrm{n}=5)(38 \pm 14.9, \mathrm{p}=0.0088 ; 47 \pm 15.4, \mathrm{p}=0.0164 ; 51 \pm 18.6, \mathrm{p}=0.0186 ; 35 \pm 6.6$ and $23 \pm 10$, $\mathrm{p}=0.0321)$ as compared to control group $(\mathrm{n}=5)(69 \pm 4.2,74 \pm 1.4,82 \pm 3,30 \pm 3.7$ and 40 \pm 5.4$)$ in spleen cell suspension. The results are presented as a percentage from NK1.1 ${ }^{+}$cells (mean \pm SD).
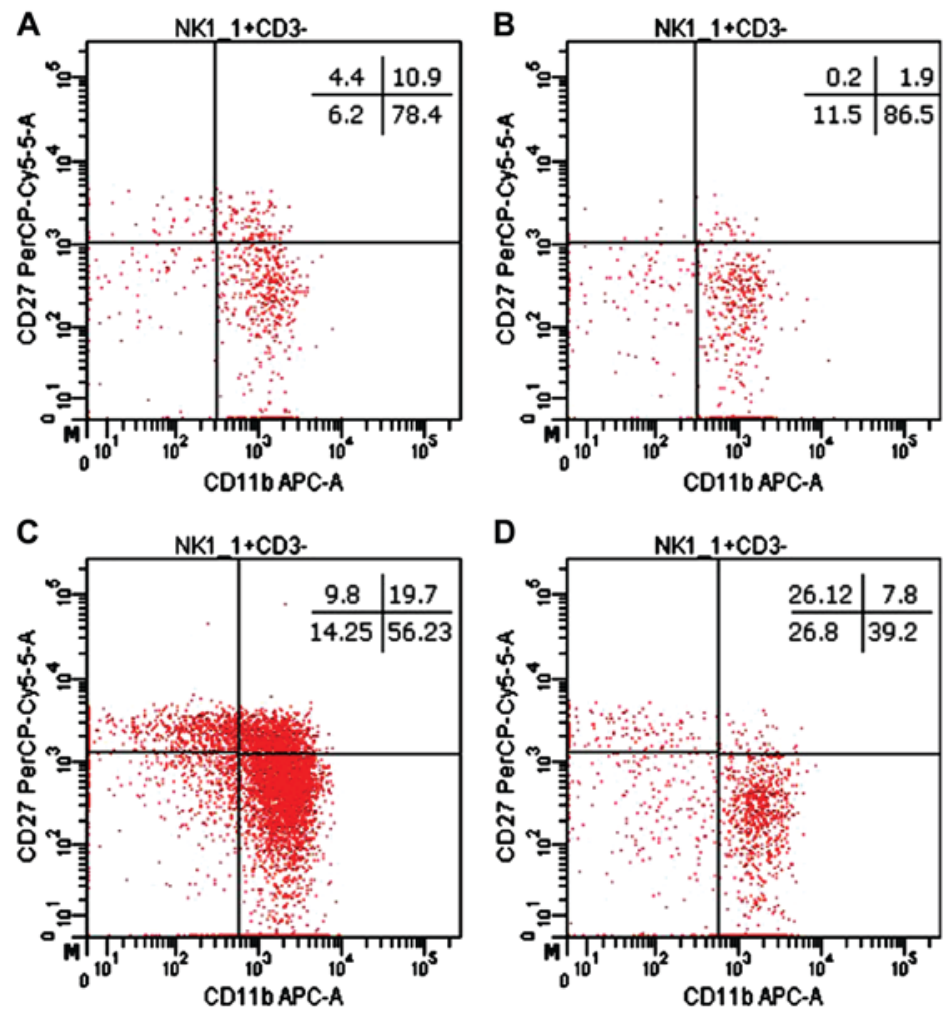

Figure 8. Expression of CD11b and CD27 for NK1.1+ cells in PB and spleen cell suspension. (A) Control group, PB; (B) MbM, PB; (C) Control group, spleen cell suspension; and (D) MbM, spleen cell suspension.

and a decrease of T-CD8 ${ }^{+}$lymphocytes in MbM compared to the control group, in both PB and spleen cell suspension, but with no statistical significance. T-CD4/T-CD8 ratio is higher in MbM compared to control group, but the differences between experimental groups are not statistically significant. Analysis of B lymphocytes and NK cells revealed statistically significant differences between the two experimental groups in both $\mathrm{PB}$ and spleen cell suspension. B-CD19+ lymphocytes were significantly decreased in $\mathrm{MbM}\left(\mathrm{p}=2 \times 10^{-7}\right.$ in $\mathrm{PB}$; $\mathrm{p}=2 \times 10^{-9}$ in spleen cell suspension) compared to the control group. Percentages of NK1.1 $1^{+}$cells increased significantly in melanoma-bearing mice in the $\mathrm{PB}(\mathrm{p}=0.001)$ and decreased in spleen cell suspension $\left(p=7 \times 10^{-6}\right)$. Evaluation of lymphocyte populations from PB and spleen cell suspension revealed an altered distribution in tumor-bearing mice as compared to control mice. The main changes were observed in B lymphocytes and NK cells, the data obtained for these populations in MbM differed significantly from those obtained for the control group, in both PB and spleen cell suspension.

Several surface markers were investigated in MbM (both in $\mathrm{PB}$ and spleen cell suspension) to assess NK cell phenotype, thus lineage markers: CD161 (NK1.1), CD3e; activation and maturation markers: CD335 (NKp46), CD69, CD45R (B220), CD11c, CD49b (DX5), CD11b, CD43, CD27, KLRG1; markers for cytokine receptors: CD25 (IL-2R $\alpha$ ), CD122 (IL-2R/IL-15R $\beta$ ), CD132 (common $\gamma$ chain). 
A

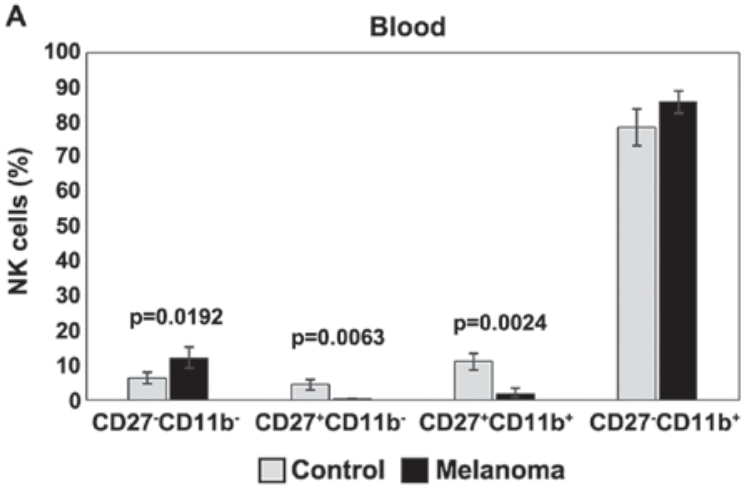

B

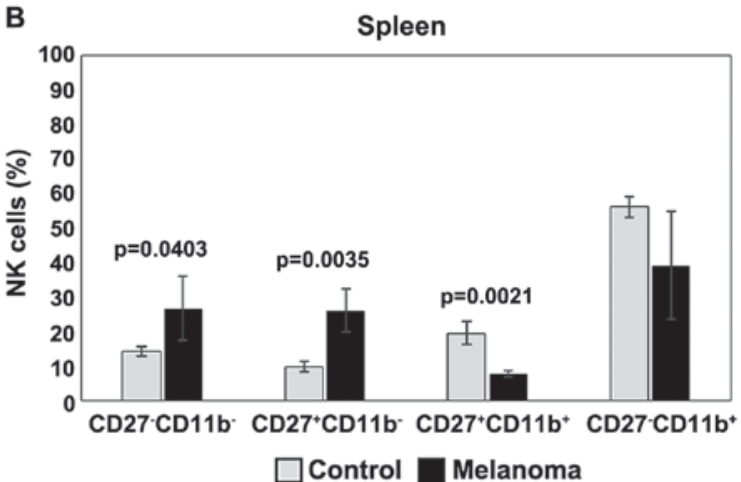

Figure 9. Distribution of CD27/CD11b/NK1.1 ${ }^{+}$subsets. (A) Distribution of CD27 CD11b NK1.1 $1^{+}$subsets in PB. CD27 CD11b, CD27 $7^{+} \mathrm{CD} 11 \mathrm{~b}, \mathrm{CD}^{-} 7^{+} \mathrm{CD} 11 \mathrm{~b}^{+}$ and $\mathrm{CD} 2 \mathrm{CD}^{-\mathrm{CD}^{+}}$cells in $\mathrm{MbM}(\mathrm{n}=5)(12 \pm 3, \mathrm{p}=0.0192 ; 0.2 \pm 0.2, \mathrm{p}=0.0063 ; 2 \pm 1, \mathrm{p}=0.0024$ and $86 \pm 3)$ and the control group $(\mathrm{n}=5)(6 \pm 1.6,4 \pm 1.5,11 \pm 2.4$ and

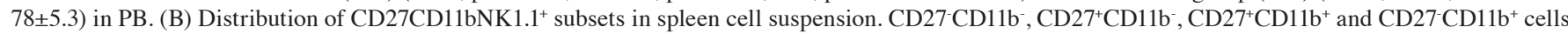
in $\mathrm{MbM}(\mathrm{n}=5)(27 \pm 9.3, \mathrm{p}=0.0403 ; 26 \pm 6.2, \mathrm{p}=0.0035 ; 8 \pm 1, \mathrm{p}=0.0021$ and $39 \pm 15.7)$ and the control group $(\mathrm{n}=5)(14 \pm 1.4,10 \pm 1.5,20 \pm 3.4$ and $56 \pm 3)$ in $\mathrm{PB}$. The results are presented as a percentage from NK1.1 $1^{+}$cells (mean $\pm \mathrm{SD}$ ).

A

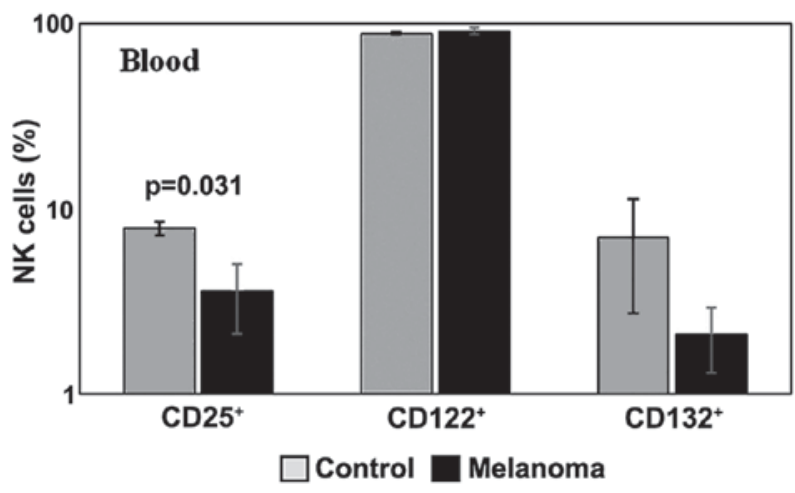

B

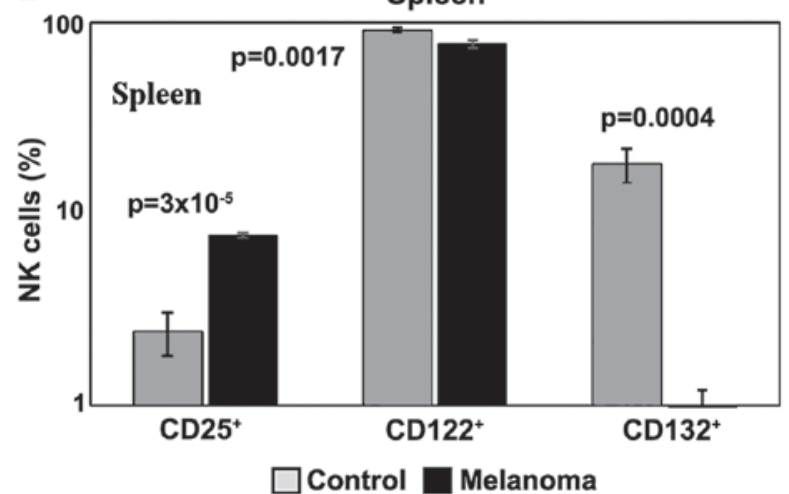

Figure 10. Expression of CD25, CD122 and CD132 for NK1.1 cells. (A) Expression of CD25, CD122 and CD132 for NK1.1 $1^{+}$cells in PB. CD25+, CD122 ${ }^{+}$ and $\mathrm{CD} 132^{+}$cells in $\mathrm{MbM}(\mathrm{n}=5)(4 \pm 1.5, \mathrm{p}=0.031 ; 91 \pm 4.1$ and $2 \pm 0.8)$ and the control group $(\mathrm{n}=5)(8 \pm 0.6,89 \pm 1.3$ and $7 \pm 4.3)$ in PB. (B) Expression of CD25, $\mathrm{CD} 122$ and $\mathrm{CD} 132$ for NK1.1 $1^{+}$cells in spleen cell suspension. $\mathrm{CD} 25^{+}, \mathrm{CD} 122^{+}$and $\mathrm{CD} 132^{+}$cells in $\mathrm{MbM}(\mathrm{n}=5)\left(8 \pm 0.2, \mathrm{p}=3 \times 10^{-5} ; 77 \pm 3.6, \mathrm{p}=0.0017\right.$ and $1 \pm 0.4$ $\mathrm{p}=0.0004)$ as compared to control group $(\mathrm{n}=5)(2 \pm 0.6,91 \pm 2.6$ and $18 \pm 3.6)$ in spleen cell suspension. The results are presented as a percentage from NK1.1 cells $($ mean $\pm \mathrm{SD})$.

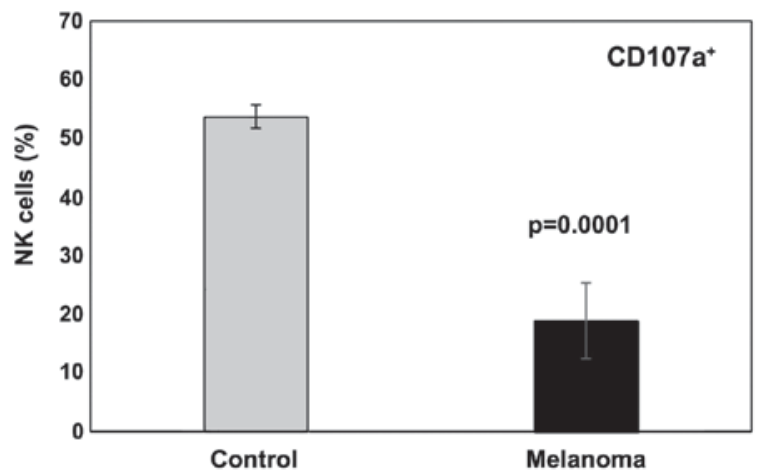

Figure 11. Expression of CD107a for NK1.1 $1^{+}$cells in spleen cell suspension. $\mathrm{CD} 107 \mathrm{a}^{+}$cells in $\mathrm{MbM}(\mathrm{n}=5)(19 \pm 6.5, \mathrm{p}=0.0001)$ and the control group $(\mathrm{n}=5)$ $(54 \pm 2)$ in spleen cell suspension. The results are presented as a percentage from NK1.1 $1^{+}$cells (mean $\pm \mathrm{SD}$ ).

NKp46 is one of the three members of the natural cytotoxicity receptor group and an important regulator of NK cell function. Signalling through the NKp46 receptor induces NK cell activation processes resulting in an increased cyto-

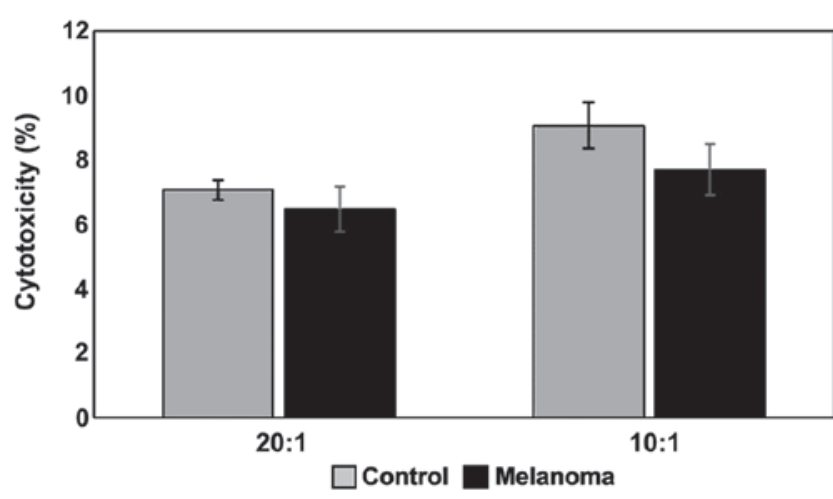

Figure 12 . NK cytotoxicity against tumor target cells. Cytotoxicity assay against YAC-1 target cells at E:T ratio 20:1 and 10:1 in MbM (n=5) (6.5 \pm 0.7 , $7.7 \pm 0.8)$ and the control group $(n=5)(7.1 \pm 0.3,9.1 \pm 0.7)$. The results are presented as a percentage of cytotoxicity (mean $\pm \mathrm{SD}$ ).

kine production and release of cytolytic granules. NKp46 is involved in tumor cell recognition $(20,21)$ and is found on all mature NK cells. It is upregulated in humans and mice during NK cell maturation. In this study we observed a decrease in 
NKp46 expression in both PB and spleen cell suspension for $\mathrm{MbM}$ compared to the control group. Only in PB significant differences were observed between the two $(\mathrm{p}<0.05)$.

Activation and maturation markers of NK cells include CD69, an early activation marker on T lymphocytes and NK cells (22-24), and CD11c (25), a member of $\beta 2$ integrin family. CD45R (B220) modulates many processes such as differentiation, division and cellular development and is essential in the development of B lymphocytes but is also present on T lymphocytes and NK cells. Activation of NK cells leads to an increased expression of B220 on the cell membrane. The main change observed in PB was the significant decrease of CD11c in melanoma $(\mathrm{p}<0.05)$ while the levels of expression for CD69 and B220 were similar for the two experimental groups. In spleen cells suspension, an increased expression of these activation markers was observed. Significant differences $(\mathrm{p}<0.05)$ were obtained between the experimental groups ( $\mathrm{MbM}$ and control group) for all three activation/maturation markers analyzed.

B220 ${ }^{+} \mathrm{CD} 11 \mathrm{c}^{+} \mathrm{NK} 1.1^{+}$cells show functional features similar to the human CD56 $6^{\text {bright }}$ cell subset which is present in lymphoid organs and produces IFN- $\gamma$ (26). In humans, the NK cell population is divided in two subsets: CD56 ${ }^{\mathrm{dim}}$ and CD56 $6^{\text {bright }}$. The CD56 ${ }^{\mathrm{dim}}$ population predominates in the blood and on inflammatory sites, displays high cytotoxic potential, expresses MHC-I specific inhibitory receptors and is considered to consist of generally terminally differentiated cells. CD56 $6^{\text {bright }}$ cells are predominant in lymph nodes, secrete cytokines, have a low cytotoxic potential, and are considered precursors of CD56 ${ }^{\text {dim }}$ cells. The CD56 ${ }^{\text {bright }}$ subset in humans represents $>10 \%$ of $\mathrm{NK}$ cells in $\mathrm{PB}$, while $\mathrm{CD} 56^{\mathrm{dim}}$ cells are predominant in spleen (over $85 \%$ ). Previous studies on breast, head and neck cancer showed a decrease in the percentage of CD56 $6^{\text {bright }}$ in PB and an increase in secondary lymphoid organs (27). Our data obtained for tumor-bearing mice showed a decrease in the percentage of $\mathrm{B} 220^{+} \mathrm{CD} 11 \mathrm{c}^{+} \mathrm{NK} 1.1^{+}$cells in $\mathrm{PB}$, as well as a significant increase in the spleen $(\mathrm{p}<0.01)$.

The development of NK cells occurs mainly in the bone marrow. The NK cell lineage commitment occurs with the increase of $\beta$-IL-2/IL-15R (CD122) chain expression followed by the acquisition of the NK1.1 marker in B6 mice. NK maturation can be discussed in terms of phenotype and functional capacity. During this step-wise maturation, integrin expression CD49b (DX5) defines the early stages. After CD49b acquisition, bone marrow NK cells upregulate the expression of CD11b and CD43. This is strongly correlated with the capacity of NK cells to produce large amounts of IFN- $\gamma$ (28). After maturation, NK cells migrate to different lymphoid and non-lymphoid organs, where most NK cells express high levels of CD49b, CD11b and CD43. After migration, the NK cells continue to adapt to the environment, downregulate CD27 expression and upregulate KLRG1 expression (29). KLRG1 is another marker associated with the maturation of NK cells (30). KLRG1 expression on mature NK cells allows identification of their terminal differentiation status associated with a reduction in proliferation and effector functions (24). In this study, analysis of CD49b, CD11b, CD43 and KLRG1 expression in $\mathrm{PB}$ revealed similar levels for $\mathrm{MbM}$ and control mice. The expression of CD27 is downregulated in MbM, and the differences between the experimental groups are significant $(\mathrm{p}=0.001)$. Significantly lower levels of NK cells expressing CD49b, CD11b, CD43 and KLRG1 were observed in spleen cell suspension in $\mathrm{MbM}(\mathrm{p}<0.05)$.

In mice, depending on the expression of CD11b, two types of NK cell populations were identified: CD11b- and CD11 ${ }^{+}$. $\mathrm{CD}_{11 b^{-}} \mathrm{NK}$ cell population is the major population in new-born mice; in adults it is mainly found in bone marrow, lymph nodes, liver and has a high proliferation rate. The $\mathrm{CD} 11 \mathrm{~b}^{+}$population is mainly present in $\mathrm{PB}$, spleen and lung. Compared to CD11b NK cells, it has a more powerful effector function.

CD27, a member of the TNFR superfamily, is an important marker that can be used to define NK cell subsets. The distribution of CD27 and CD11b markers can be used to divide murine NK cells into 4 subsets defining different maturation stages (31). The CD27-CD11b- phenotype defines immature $\mathrm{NK}$ cells, $\mathrm{CD} 27^{+} \mathrm{CD} 11 \mathrm{~b}^{-}$suggest an early maturation stage, while $\mathrm{CD} 27^{+} \mathrm{CD} 11 \mathrm{~b}^{+}$and $\mathrm{CD} 27^{-} \mathrm{CD} 11 \mathrm{~b}^{+}$are specific to mature NK cells. These phenotypic changes also reflect variations in the functional activity of NK cells-double positive mature cells exhibit the highest responsiveness, while CD27$\mathrm{CD}_{11} \mathrm{~b}^{+} \mathrm{KLRG}^{+}$represents the terminal stage. Our results suggested that the distribution of mature NK cell subsets in tumor-bearing mice are different from that of healthy mice. In PB we observed significant differences between MbM and the control mice for immature $\mathrm{CD}^{2} 7^{-} \mathrm{CD}^{-11 b^{-}} \mathrm{NK}$ cells $(\mathrm{p}<0.05)$, early mature $\mathrm{CD} 27^{+} \mathrm{CD} 11 \mathrm{~b}^{-}(\mathrm{p}<0.01)$ and mature $\mathrm{CD} 27^{+} \mathrm{CD} 11 \mathrm{~b}^{+}$ $(\mathrm{p}<0.01)$ NK cells. The CD27-CD11b ${ }^{+} \mathrm{NK}$ subset was increased in $\mathrm{MbM}$, but without statistical significance. CD27 CD11b $\mathrm{CD} 27^{+} \mathrm{CD} 11 \mathrm{~b}^{-}$and $\mathrm{CD} 27^{+} \mathrm{CD} 11 \mathrm{~b}^{+} \mathrm{NK}$ subsets in spleen cell suspension revealed increased values for immature $(\mathrm{p}<0.05)$ and early mature $(\mathrm{p}<0.01) \mathrm{NK}$ cells, while the percentage of mature NK cells is lower in $\mathrm{MbM}$ than in the control group $(\mathrm{p}<0.01) . \mathrm{CD}^{-} \mathrm{CD}^{-} 11 \mathrm{~b}^{+} \mathrm{NK}$ subset was decreased in MbM, but without statistical significance. Comparing the distribution of NK cell subsets between healthy and MbM revealed a significant decrease in mature NK cell subsets suggesting that the tumor influences NK cell regulation of maturation and homeostasis. An increase in the number of immature NK cells suggests that the tumor can render NK cells less tumoricidal and thus contribute to cancer progression.

The NK cell lineage commitment, proliferation, activation, and functional capacity of NK cells are controlled by various cytokines, among which the most important are IL-2, IL-7, IL-15 and IL-21. All these cytokines share the $\gamma$-receptor (CD132) chain, and IL-2 and IL-15 share the $\beta$ receptor subunit (CD122). We observed a decreased expression in the common $\gamma$ receptor subunit, both in blood and spleen cell suspension $(\mathrm{p}<0.001)$ in $\mathrm{MbM}$, and a decrease in receptor subunit $\beta$ in spleen $(\mathrm{p}<0.01)$. Also, we noted a decrease in IL-2 $\alpha$ receptor subunit $(\mathrm{CD} 25)$ expression in PB $(\mathrm{p}<0.05)$ in $\mathrm{MbM}$, and an increase in spleen cell suspension $(\mathrm{p}<0.001)$.

Functional characterization of NK cells from cell suspensions was performed by evaluating the degranulation of NK cells (effector cells) after exposure to target tumor cells (YAC-1 cells) and the release of LDH to evaluate the cytotoxic effect that NK cells exhibit on tumor cells. CD107a expression change is reflecting NK cell degranulation and it was measured by flow cytometry, assessing thus NK cytotoxicity. NK cell degranulation capacity (expressed by the release of cytolytic granules containing granzymes and perforins in the presence 
of tumor target cells) is a demonstration of the NK effector function (i.e., the ability to kill tumor cells). The surface of the cytolytic granules is covered by CD107a or LAMP-1, a highly glycosylated protein that makes up $~ 50 \%$ of the lysosomal membrane proteins. After degranulation, CD107a is exposed on the surface of cytotoxic cells. Externalization of CD107a has been shown to be a marker of NK cell, T-CD8 ${ }^{+}$ and $\mathrm{T}-\mathrm{CD} 4^{+}$cell degranulation (32). In this study a significant decrease in NK cells degranulation capacity (the effector function) was detected in MbM and the differences between the experimental groups were statistically significant $(\mathrm{p}<0.001)$. Regarding cytotoxicity inflicted upon YAC-1 cells the actual differences between studied groups can be seen only in the 10:1 (effector cell:target cell) ratio, with a decrease in melanomabearing mice compared to controls. NK cytotoxicity to tumor target cells was assessed by measuring the release of LDH from dead cells in a culture medium. MbM NK cells showed a lower cytotoxicity against target cells (YAC-1) compared to the control group. Even though the decrease in cytotoxicity is not statistically significant, the data suggest a decrease of the tumoricidal efficiency of NK cells.

In patients diagnosed with melanoma evaluating the NK subpopulation percentage should be combined with NK activity evaluation (degranulation potential and cytolytic activity) to additionally monitor therapy efficacy.

In conclusion, lymphocyte populations are differently distributed in PB and in secondary lymphoid organs, like the spleen in melanoma-bearing animals. Tumors induce the decrease in the percentage of B lymphocytes and NK cells in the spleen. Experimental data show a statistical significant reduction of the percentage of $\mathrm{NK}$ cells in MbM compared to control animals. Analysis of NK cell subsets, defined by the differential expression of CD27 and CD11b demonstrated a significant difference in the distribution of NK cell subsets, with the mature subset being dominant in the healthy mice. Also, we found a decrease of both CD43 and KLRG1 (markers commonly used for terminally differentiated NK cells), and a downregulation of activating receptor NKp46 in MbM.

The evaluation of the distribution of NK cells revealed a significant decrease in mature NK cell subsets in $\mathrm{MbM}$, suggesting that the tumor alters NK cell maturation and homeostasis. An increase of the number of immature NK cells suggests that the tumor can cause NK cells to become less tumoricidal and thus contributes to cancer progression.

These results are confirmed by a decrease in NK cell functions in MbM compared to the control group. Cytokine secretion is reduced for $\gamma$ chains of IL-2, IL-7, IL-15 and IL-21 (33-38). Degranulation is also impaired in MbM, with effect on the cytotoxic function.

Overall, our findings highlight a complex functional disorder of NK cells during tumor development, both in the terms of composition of active cytotoxic NK cell subsets, and of tumoricidal activity efficiency. We showed that NK cells from the spleen in a MbM model are reduced as percentage and have different phenotypic characteristics than NK cells from a healthy mouse. In case of MbM CD11b CD27- $\mathrm{NK}$ cells, which have been defined as immature NK cells, they are increased both in PB and the spleen.

It is clear that the decrease of NK activity is a tumor development-associated phenomenon, which can be caused by both tumoral factors and by dysfunctions in the development and maturation of NK cells (39). This could suggest that the tumor may render NK cells less cytotoxic and thereby it contributes to cancer progression and moreover NK populations can be used as tumor development cell biomarkers. Hence, this study provided new insights into NK cell phenotypic changes, proving that the analysis of NK cell phenotype and cytokine secretion markers in PB may be useful in assessing the impairment degree of the antitumor immune response. Re-adjusting this response may become a target for new approaches to cancer immunotherapy (40).

\section{Acknowledgements}

Not applicable.

\section{Funding}

This study was supported by Core Program, implemented with the support NASR, projects nos. 18.21.02.01 and 18.21.02.02; grant PN-III-P1-1.2-PCCDI-2017-0341/2018 and 7PFE/16.10.2018.

\section{Availability of data and materials}

The data sets used and/or analysed during the present study are available from the corresponding author on reasonable request.

\section{Authors' contributions}

GI, MS, RIH, CC, MN and CU contributed to the conception and design of the study, the acquisition, analysis and interpretation of the data, drafting the manuscript and revising it critically for important intellectual content. GI, MS, ANM, IRP, DC, OB and CC were responsible for the acquisition, analysis and interpretation of the data, drafting the manuscript and revising it critically for important intellectual content. All authors read and approved the final manuscript.

\section{Ethics approval and consent to participate}

The study protocol was approved by the Ethics Committee of 'Victor Babeș' Institute and by the National Sanitary Veterinary and Food Safety Authority through project authorization no. 388/22.03.2018 (Bucharest, Romania).

\section{Patient consent to participate}

Not applicable.

\section{Competing interests}

The authors declare that they have no competing interests.

\section{References}

1. Chin L, Garraway LA and Fisher DE: Malignant melanoma: Genetics and therapeutics in the genomic era. Genes Dev 20: 2149-2182, 2006. 
2. Lakshmikanth $\mathrm{T}$ and Johansson $\mathrm{MH}$ : Current perspectives on immunomodulation of NK cells in melanoma. In: Melanoma in the Clinic - Diagnosis, Management and Complications of Malignancy. Mandi M (ed). InTech, Rijeka, pp133-162, 2011.

3. Serban ED, Farnetani F, Pellacani G and Constantin MM: Role of in vivo reflectance confocal microscopy in the analysis of melanocytic lesions. Acta Dermatovenerol Croat 26: 64-67, 2018

4. Rangwala S and Tsai KY: Roles of the immune system in skin cancer. Br J Dermatol 165: 953-965, 2011

5. Lupu M, Caruntu A, Caruntu C, Papagheorghe LML, Ilie MA, Voiculescu V, Boda D, Constantin C, Tanase C, Sifaki M, et al: Neuroendocrine factors: The missing link in non-melanoma skin cancer (Review). Oncol Rep 38: 1327-1340, 2017.

6. Caruntu C, Boda D, Constantin C, Caruntu A and Neagu M: Catecholamines increase in vitro proliferation of murine B16F10 melanoma cells. Acta Endocrinol (Copenh) 10: 545-558, 2014.

7. Neagu M: The immune system - a hidden treasure for biomarker discovery in cutaneous melanoma. Adv Clin Chem 58: 89-140, 2012.

8. Holtan SG, Creedon DJ, Thompson MA, Nevala WK and Markovic SN: Expansion of CD16-negative natural killer cells in the peripheral blood of patients with metastatic melanoma. Clin Dev Immunol 2011: 316314, 2011.

9. Imai K, Matsuyama S, Miyake S, Suga K and Nakachi K: Natural cytotoxic activity of peripheral-blood lymphocytes and cancer incidence: An 11-year follow-up study of a general population. Lancet 356: 1795-1799, 2000.

10. Dons'koi BV, Chernyshov VP and Osypchuk DV: Measurement of NK activity in whole blood by the CD69 upregulation after co-incubation with K562, comparison with NK cytotoxicity assays and CD107a degranulation assay. J Immunol Methods 372 : 187-195, 2011.

11. Fehniger TA, Cooper MA, Nuovo GJ, Cella M, Facchetti F, Colonna $\mathrm{M}$ and Caligiuri MA: CD56 $6^{\text {bright }}$ natural killer cells are present in human lymph nodes and are activated by T cell-derived IL-2: A potential new link between adaptive and innate immunity. Blood 101: 3052-3057, 2003.

12. Colucci F, Caligiuri MA and Di Santo JP: What does it take to make a natural killer? Nat Rev Immunol 3: 413-425, 2003.

13. Ursaciuc C, Surcel M, Huică R, Ciotaru D, Dobre M, Pîrvu IR, Cirimbei C, Mischianu D, Bratu O, Isvoranu G, et al: CD56 $6^{\text {dim/CD5 }}$ bright $^{\text {bK }}$ cell subpopulations and CD16/CD57 expression correlated with tumor development stages. S East Eur J Immunol 2016: 1-5, 2016.

14. Hayakawa Y and Smyth MJ: CD27 dissects mature NK cells into two subsets with distinct responsiveness and migratory capacity. J Immunol 176: 1517-1524, 2006

15. Inng jerdingen $M$, Kveberg L, Naper $C$ and Vaage JT: Natural killer cell subsets in man and rodents. Tissue Antigens 78: 81-88, 2011.

16. Sun JC and Lanier LL: NK cell development, homeostasis and function: Parallels with $\mathrm{CD}^{+} \mathrm{T}$ cells. Nat Rev Immunol 11: 645-657, 2011.

17. Chiossone L, Chaix J, Fuseri N, Roth C, Vivier E and Walzer T: Maturation of mouse NK cells is a 4-stage developmental program. Blood 113: 5488-5496, 2009.

18. National Research Council: Animal care and use program In: Guide for the Care and Use of Laboratory Animals. 8th edition. National Academy Press, Washington, DC, pp11-35, 2011.

19. Faustino-Rocha A, Oliveira PA, Pinho-Oliveira J, Teixeira-Guedes C, Soares-Maia R, da Costa RG, Colaço B, Pires MJ, Colaço J, Ferreira R and Ginja M: Estimation of rat mammary tumor volume using caliper and ultrasonography measurements. Lab Animal 42: 217-224, 2013

20. Freud AG, Zhao S, Wei S, Gitana GM, Molina-Kirsch HF, Atwater SK and Natkunam Y: Expression of the activating receptor, NKp46 (CD335), in human natural killer and T-cell neoplasia. Am J Clin Pathol 140: 853-866, 2013.

21. Hadad U, Thauland TJ, Martinez OM, Butte MJ, Porgador A and Krams SM: NKp46 clusters at the immune synapse and regulates NK cell polarization. Front Immunol 6: 495, 2015.
22. North J, Bakhsh I, Marden C, Pittman H, Addison E, Navarrete C, Anderson R and Lowdell MW: Tumor-primed human natural killer cells lyse NK-resistant tumor targets: Evidence of a two-stage process in resting NK cell activation. J Immunol 178: 85-94, 2007.

23. Iizuka K, Chaplin DD, Wang Y, Wu Q, Pegg LE, Yokoyama WM and $\mathrm{Fu}$ YX: Requirement for membrane lymphotoxin in natural killer cell development. Proc Natl Acad Sci USA 96: 6336-6340, 1999.

24. Fogel LA, Sun MM, Geurs TL, Carayannopoulos LN and French AR: Markers of nonselective and specific NK cell activation. J Immunol 190: 6269-6276, 2013.

25. Burt BM, Plitas G, Stableford JA, Nguyen HM, Bamboat ZM, Pillarisetty VG and DeMatteo RP: CD11c identifies a subset of murine liver natural killer cells that responds to adenoviral hepatitis. J Leukoc Biol 84: 1039-1046, 2008.

26. Blasius AL, Barchet W, Cella M and Colonna M: Development and function of murine $\mathrm{B} 220^{+} \mathrm{CD} 11 \mathrm{c}^{+} \mathrm{NK} 1.1^{+}$cells identify them as a subset of NK cells. J Exp Med 204: 2561-2568, 2007.

27. Michel T, Poli A, Cuapio A, Briquemont B, Iserentant G, Ollert $\mathrm{M}$ and Zimmer J: Human CD56 ${ }^{\text {bright }} \mathrm{NK}$ cells: An update. J Immunol 196: 2923-2931, 2016.

28. Richards JO, Chang X, Blaser BW, Caligiuri MA, Zheng P and Liu Y: Tumor growth impedes natural-killer-cell maturation in the bone marrow. Blood 108: 246-252, 2006.

29. Clinthorne JF, Beli E, Duriancik DM and Gardner EM: NK cell maturation and function in C57BL/6 mice are altered by caloric restriction. J Immunol 190: 712-722, 2013.

30. Huntington ND, Tabarias H, Fairfax K, Brady J, Hayakawa Y, Degli-Esposti MA, Smyth MJ, Tarlinton DM and Nutt SL: NK cell maturation and peripheral homeostasis is associated with KLRG1 upregulation. J Immunol 178: 4764-4770, 2007.

31. Ballas ZK, Buchta CM, Rosean TR, Heusel JW and Shey MR: Role of NK cell subsets in organ-specific murine melanoma metastasis. PLoS One 8: e65599, 2013.

32. Alter G, Malenfant JM and Altfeld M: CD107a as a functional marker for the identification of natural killer cell activity. J Immunol Methods 294: 15-22, 2004.

33. Neagu M, Constantin $\mathrm{C}$ and Longo $\mathrm{C}$ : Chemokines in the melanoma metastasis biomarkers portrait. J Immunoassay Immunochem 36: 559-566, 2015

34. Neagu M, Constantin C and Tanase C: Immune-related biomarkers for diagnosis/prognosis and therapy monitoring of cutaneous melanoma. Expert Rev Mol Diagn 10: 897-919, 2010.

35. Neagu M, Caruntu C, Constantin C, Boda D, Zurac S, Spandidos DA and Tsatsakis AM: Chemically induced skin carcinogenesis: Updates in experimental models (Review). Oncol Rep 35: 2516-2528, 2016.

36. Zurac S, Neagu M, Constantin C, Cioplea M, Nedelcu R, Bastian A, Popp C, Nichita L, Andrei R, Tebeica T, et al: Variations in the expression of TIMP1, TIMP2 and TIMP3 in cutaneous melanoma with regression and their possible function as prognostic predictors. Oncol Lett 11: 3354-3360, 2016.

37. Isvoranu G, Marinescu B, Surcel M, Ursaciuc C and Manda G: Immunotherapy in cancer - in vivo study of the anti-tumor activity of the IL-15/IL-15R alfa combination in an experimental model of melanoma. Farmacia 63: 631-636, 2015.

38. Isvoranu G: The memory activation of NK cells: New methods in cancer immunotherapy. In: Immunotherapy: Myths, Reality, Ideas, Future. Metodiev K (ed). IntechOpen, London, pp201-219, 2017.

39. Zaharescu I, Moldovan AD and Tanase C: Natural killer (NK) cells and their involvement in different types of cancer. Current status of clinical research. J Mind Med Sci 4: 31-37, 2017.

40. Tanase CP, Albulescu R and Neagu M: Application of 3D hydrogel microarrays in molecular diagnostics: Advantages and limitations. Expert Rev Mol Diagn 11: 461-464, 2011. International (CC BY-NC-ND 4.0) License. 